\title{
Microinvasive squamous cell carcinoma of uterine cervix with superficial spread to endometrium: a rare case report
}

\author{
Ritu Arora ${ }^{1}$, Nisha Bhagat ${ }^{2 *}$, Rajnish Raj $^{3}$
}

\begin{abstract}
${ }^{1}$ Department of Pathology, North Delhi Municipal Corporation Medical College and Hindu Rao Hospital, New Delhi, India

${ }^{2}$ Department of Obstetrics and Gynecology, Government Medical College, Amritsar, Punjab, India

${ }^{3}$ Department of Psychiatry, Government Medical College, Patiala, Punjab, India
\end{abstract}

Received: 20 March 2017

Accepted: 21 April 2017

\section{*Correspondence:}

Dr. Nisha Bhagat,

E-mail: nishabhagat07@yahoo.com

Copyright: (c) the author(s), publisher and licensee Medip Academy. This is an open-access article distributed under the terms of the Creative Commons Attribution Non-Commercial License, which permits unrestricted non-commercial use, distribution, and reproduction in any medium, provided the original work is properly cited.

\begin{abstract}
Microinvasive squamous cell carcinoma of uterine cervix is defined as carcinoma with invasion of less than $5 \mathrm{~mm}$ penetration of the stroma. The spread to uterine corpus occurs rarely, but on lateral spread it involves parametrium and deep myometrium via lymphatic dissemination. Less than 30 cases are reported in literature of superficial spread of microinvasive carcinoma of cervix. We report a case of microinvasive squamous cell carcinoma of cervix with metastasis to uterine corpus due to superficial spread.
\end{abstract}

Keywords: Cervix, Diagnostic and statistical manual of mental disorder, Endometrium, Squamous cell carcinoma (SCC), Superficial spread

\section{INTRODUCTION}

Squamous cell carcinoma of cervix is the most common gynaecological malignancy in India. ${ }^{1}$ It generally invades into the uterine wall, but in rare cases, spreads superficially to the inner surface of uterus, thereby replacing endometrium. Such dissemination occurred very rarely and is known as superficial spread. ${ }^{2}$

Microinvasive squamous cell carcinoma of cervix is a microscopic lesion with a maximum stromal spread of $5.0 \mathrm{~mm}$ and maximum transverse spread of $7.0 \mathrm{~mm}$. There are two sub-categories i.e., stage IA1 tumour that invades to a depth of $3 \mathrm{~mm}$ or less with lateral spread less than $7 \mathrm{~mm}$, and stage IA2 tumour that invades to a depth of 3-5 mm and less than $7 \mathrm{~mm}$ of lateral spread. ${ }^{3}$ Cervical carcinoma usually extends by lateral spread to involve parametria by a path of least resistance through lymphatic invasion of uterine wall. ${ }^{4}$ The case of microinvasive squamous cell carcinoma of cervix is reported for its rarity, which was assessed for malignancy on International Federation of Gynecology and Obstetrics (FIGO) and graded as FIGO stage 1A1 with a superficial spread that replaced total columnar epithelium cells of corpus uteri.

\section{CASE REPORT}

A 67-year old multiparous, female, P2 L2 reported to the OPD of Department of Obstetrics and Gynecology, Government Medical College, Amritsar with chief complaints of postmenopausal bleeding and discharge per vaginum for the last 2 months and symptoms of sadness, decreased sleep, worry and palpitation for the last one month. She was menopausal for the last 10 years. There was no current or past history of any hyper or hypothyroidism, tuberculosis, epilepsy and substance 
abuse of alcohol, drugs etc. Past psychiatric and personal history of sexual contact was stated to be normal. Family history for carcinoma was also remarkably normal. On general physical examination, patient was conscious, cooperative, well oriented to time, place, and person. Moderately build and nourished. No history of anaemia, jaundice or cyanosis. She was normotensive but diabetic for the last 15 years and had a normal height and body mass index. On mental state examination, patient's mood was sad and anxious, affect appropriate. Thought process, content, perception, higher cognitive functions, judgment and insight to the illness were normal. Per speculum examination showed cervix flushed to the vault, with a pinpoint os and had normal visual inspection after acetic acid (VIA) and visual inspection after Lugol's iodine (VILI).

Local per vaginal examination revealed an enlarged uterus of 10-12 weeks' size, which was soft and flabby. All haematological parameters, laboratory screen for venereal disease research laboratory test (VDRL), human immune deficiency virus (HIV), HBsAg (Australia antigen), hepatitis $\mathrm{C}$ virus (HCV) and tumour markers etc., were within normal limits. On Dilatation and Curettage, about $5 \mathrm{ml}$ of pus was drained. The probable clinical diagnosis of pyometra secondary to cervical stenosis was made. Total abdominal hysterectomy with bilateral salpingo-oophorectomy was done. There was possibility of co-morbid psychopathology, the assessment on Diagnostic and Statistical Manual of Mental Disorder (DSM-5) revealed a clinical diagnosis of 309.28 (F43.23) Adjustment disorder with mixed anxiety and depressive mood. ${ }^{5}$ Subsequently, severity was assessed on Hospital Anxiety and Depression Scale-Anxiety (HADS-A) and Hospital Anxiety and Depression Scale-Depression (HADS-D); Clinical outcome on Clinical Global Impression- Severity Scale (CGI-S) having scores of 13, 11 and 4 respectively. 6,7

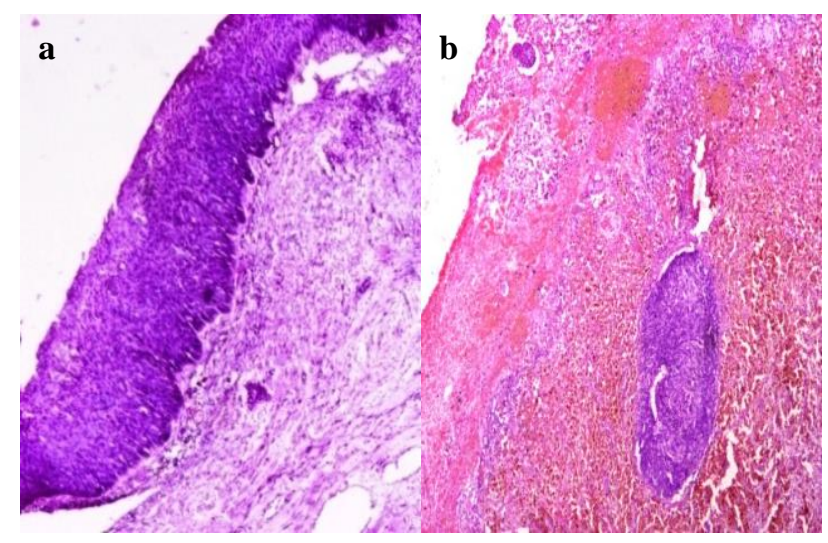

Figure 1: Cervical epithelium demonstrating (a) CIN $3(100 \times \mathrm{H}$ and $\mathrm{E})$ and (b) focus of early stromal invasion (100x $\mathrm{H}$ and $\mathrm{E})$.

These symptoms were in response to the perceived stress of recently diagnosed carcinoma of uterine cervix. It could be a normative stress reaction in patients who hear bad news. However, it was neither attributed to drug nor to premorbid anxious personality State or Trait of the patient because of her low-level scores i.e., 27 and 35 on State and Trait Anxiety Inventory (STAI). ${ }^{8}$ Patient was given psycho-education and pharmacotherapy to abate the psycho-social stressor. Lloyd and Bor, 2004 process for breaking bad news was followed. ${ }^{9}$ After 8 weeks, her HADS-A, HADS-D and Clinical Global ImpressionImprovement Scale (CGI-I) scores were 6, 9 and 1 respectively, indicating very much improvement.

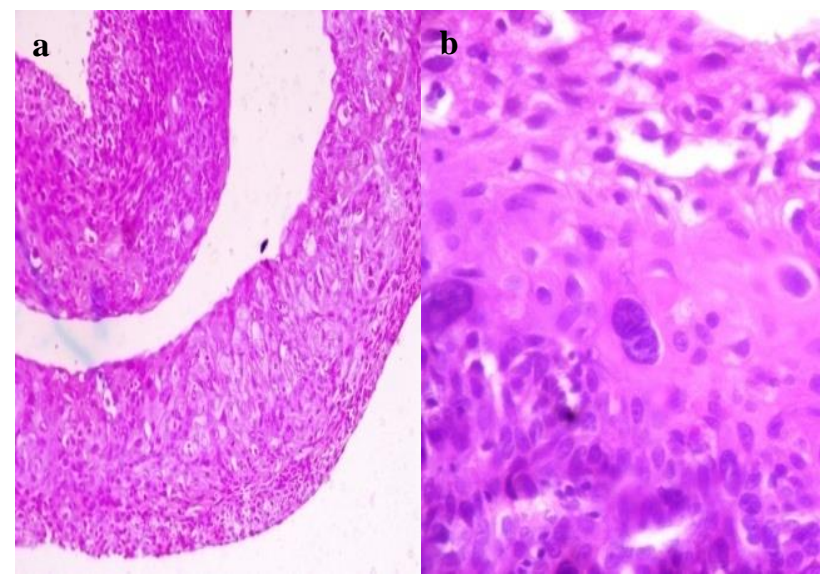

Figure 2: Section from endometrial curettings showing squamous epithelium with dysplasia and carcinoma in situ (A 100x H and E, B 400x $\mathrm{H}$ and E).

The specimen of uterus with bilateral tubes and ovaries were sent for histopathological examination. The gross examination of the sample on cut section revealed irregular uterine cavity with shaggy mucosal surface, which extended up to endocervical canal. Cervix was atrophied but without any growth. Left side of the ovary had cyst filled with pultaceous material and hairs. Microscopic examination of cervix showed ulcerated lining with dense mononuclear inflammatory infiltrate and many hemosiderin laden macrophages in the stroma. Minimal part of cervix showed high grade squamous intraepithelial lesion and carcinoma in situ of cervix (HSIL, CIN 3). Micro-section of uteri corpus had ulcerated lining and dense inflammation with many hemosiderin laden macrophages. However, endometrial glands and stroma were not visible. Therefore, multiple sections of the sample were taken. Cervix was processed on consecutive parallel blocks. Endometrial curettings were taken from the shaggy irregular mucosa of uterine body.

Multiple sections from cervix revealed features of HSIL, CIN 3 with focal superficial invasion into stroma and marked desmoplastic reaction (Figure 1). Endometrial curettings of uterus and fundus showed squamous epithelium with dysplasia and CIN (Figure 2). Corpus uteri had ulcerated lining, desmoplastic stroma showed replacement of endometrial lining by squamous epithelium with dysplasia and CIN (Figure 3). There was no evidence for invasion of endometrial stroma or 
myometrium. Left ovary had mature cystic teratoma but right ovary and both the fallopian tubes were remarkably normal. The tumour was graded as FIGO stage 1A1 (microinvasive squamous cell carcinoma of cervix with superficial spread to endometrium).

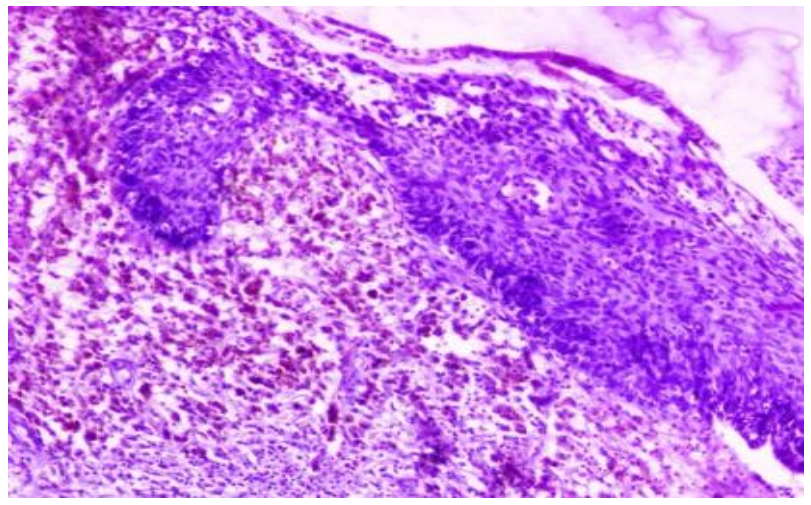

Figure 3: Photomicrograph showing extensive replacement of endometrial lining by squamous metaplastic epithelium with features of dysplasia (100x H and E).

\section{DISCUSSION}

The presence of squamous cell component in endometrium suggests the following possibilities i.e., extension from cervical cancer, squamous cell differentiation of endometrial carcinoma or primary superficial spread to endometrium. The incidence of primary endometrial squamous cell carcinoma is uncommon and range from $0.1 \%$ to $0.5 \%$ of all uterine cancers. Most of these cases have an extension of primary cervical carcinoma. However, to delineate as a primary carcinoma of endometrium, the tumour must satisfy the following criteria established by Fluhmann and later on modified by Kay i.e., no coexistent endometrial adenocarcinoma; no demonstrable connection between endometrial tumour and stratified squamous epithelium of cervix, and no primary cervical carcinoma. ${ }^{10,11}$ In present case, the presence of dysplastic squamous cell lining of endometrium signifies extension from cervical cancer. The presence of cervical stenosis and pyometra could have facilitated the propagation of cervical cancer.

On review of literature, 26 cases of cervical carcinoma with endometrial surface involvement were reported; 9 cases of carcinoma in situ (CIN); 2 cases of microinvasive carcinoma; and 15 cases of invasive cervical carcinoma. ${ }^{1,2,7,12}$ The present case showed microinvasive squamous cell carcinoma of cervix with an upward extension to uterine corpus due to a superficial spread and thus, replacing the entire surface epithelium. When squamous epithelium shows dysplastic changes on endometrial biopsy or curettage, it raises possibility of significant cervical pathology and emphasizes the importance of extensive grossing and sampling for proper diagnosis and management. The microinvasive carcinoma of cervix with uterine corpus involvement makes its management debatable. As per the guidelines of The Society of Gynecological Oncologists (SGO) such microinvasive carcinoma had no potential for metastasis or recurrence and recommends preservation of corpus uteri of women desirous of fertility. ${ }^{13}$

Treatment for stage 1A1 cancer of cervix with $<3 \mathrm{~mm}$ of stromal invasion and lack of lymphovascular space invasion (LVSI) should be managed by less radical procedure i.e., radical trachelectomy and bilateral pelvic lymphadenectomy. However, authors are of the considered view that management of this case with conservative surgery should be reconsidered because of the possibility of recurrence as it spreads to corpus. FIGO staging classification and management guidelines are silent on such cases, which are having a significant prognostic value and requires an urgent upgrade. ${ }^{1,14}$

Despite medical and surgical advancements in treatment of carcinoma, it is still frightening for the patients and poses bio-psycho-social problems e.g., anatomical and physiological loss, sexual difficulty and reduced fertility. The promiscuous lifestyle and an infection with human papilloma virus (HPV) had a causal relationship in aetiopathogenesis of cervical cancer. It is a major stressful life event and plausibly puts patient to various mental health ailments and an accentuation of cancer. ${ }^{15}$ Adjustment disorders are probably the most common diagnosis among cancer patients with prevalence of $47 \%$ and had a clinical diagnosis of $43 \%$ and $2 \%$ of personality disorder. $^{16}$ In present case, patient had co-morbid adjustment disorder with uterine cervix carcinoma, which was subsequently treated with psycho-education and pharmacological intervention e.g. selective serotonin reuptake inhibitors. Furthermore, it is recommended that larger naturalistic studies are required to identify the possible risk factors that may influence underlying pathophysiology of disease, precipitating or exacerbation of symptoms or necessitating medical attention, which is an additional health risk for the individual

\section{CONCLUSION}

There is a lack of consensus guidelines for prognosis and management of superficial spread of squamous cell carcinoma of cervix. On endometrial biopsy or curettage, these findings of squamous cell epithelium with dysplastic changes require diligent assessment and evaluation by the clinicians as it raises the possibility of significant cervical pathology.

\section{Funding: No funding sources \\ Conflict of interest: None declared \\ Ethical approval: Not required}

\section{REFERENCES}

1. Gungor T, Altinkaya SO, Ozat M, Akbay S, Mollamahmutoglu L. Unusual form of superficial spreading squamous cell carcinoma of cervix 
involving the endometrium, bilateral tubes and ovaries: a case report with literature review. Arch Gynecol Obstet. 2011;283:323-7.

2. Tan GC, Isa MR, Ng SP, Jamil YM. Unusual form of superficial spreading microinvasive squamous cell carcinoma of uterine cervix involving the endometrium of uterus. J Obstet Gynecol Res. 2004;30(5):363-7.

3. FIGO Committee on Gynaecologic Oncology. Modifications in the staging for stage I vulvar and stage I cervical cancer. Int J Gynaecol Obstet. 1995;50:215-6.

4. Agashe SR, Kulkarni MP, Momin YA, Sulhyan KR. Superficial extension of squamous cell carcinoma in situ of cervix involving endometrium, bilateral fallopian tubes and ovaries: A case report. Indian J Pathol Microbiol. 2007;50:375-7.

5. American Psychiatric Association. Diagnostic and Statistical manual of mental disorders (DSM-5), 5th ed. Arlington, VA: American Psychiatric Association, Washington DC; 2013.

6. Bjelland I, Dahl AA, Haug TT, Neckelmann D. The validity of the hospital Anxiety and Depression Scale: an update literature review. J Psychosm Res. 2002;52:69-77.

7. Beneke M, Rasmus W. Clinical global impressions (ECDEU): some critical comments. Pharmacopsychiatrie. 1992;25:171-6.

8. Spielberger CD, Gorsuch RL, Lushene PR, Vagg PR and Jacobs GA. Manual for State-Trait Anxiety Inventory: Bibliography (2nd ed) Palo Alto, CA: Consulting Psychologists Press; 1983.

9. Lloyd M, Bor R. Communication skills for medicine, 2nd edn. Edinburgh: Churchill Livingstone; 2004.
10. Fluhmann CF. Squamous epithelium in the endometrium in benign and malignant conditions. Surg Gynecol Obstet. 1928;46:309-16.

11. Kay S. Squamous-cell carcinoma of the endometrium. Am J Clin Pathol. 1974;61:264-9.

12. Kanbour AI, Stock RJ. Squamous cell carcinoma in situ of the endometrium and fallopian tube as superficial extension of invasive cervical carcinoma. Cancer. 1978;42:570-80.

13. Diaz JP, Sonoda Y, Leitao MM, Zivanovic O, Brown CL, Chi DS et al. Oncologic outcome of fertilitysparing radical trachelectomy versus radical hysterectomy for stage IB1 cervical carcinoma. Gynecol Oncol. 2008;111(2):255-60.

14. Agashe SR, Kulkarni MP, Momin YA, Sulhyan KR. Superficial extension of squamous cell carcinoma in situ of cervix involving endometrium, bilateral fallopian tubes and ovaries: a case report. Indian J Pathol Microbiol. 2007;50:375-7.

15. Ramirez AJ, Craig TK, Watson JP et al. Stress and relapse of breast cancer. $\mathrm{Br}$ Med Journal. 1989;298:291-3.

16. Derogatis LR, Marrow GR, Fetting J, Penman D, Piasetsky S, Schmale AM et al. The prevalence of psychiatric disorders among cancer patients. JAMA. 1983;249:751-7.

Cite this article as: Arora R, Bhagat N, Raj R.

Microinvasive squamous cell carcinoma of uterine cervix with superficial spread to endometrium: a rare case report. Int J Reprod Contracept Obstet Gynecol 2017;6:2644-7. 